\title{
Prevalence and correlates of Single Child Behavior among Women
}

\author{
Serajeddin Mahmoudiani ${ }^{1 *}$ \\ 1. Faculty of Economics, Management and Social Sciences, Shiraz University, Shiraz, Iran
}

Received: 28 November 2020

Accepted for publication: 19 December 2020

[EPub a head of print-12 January 2021]

Payesh: 2021; 20 (1):109-117

\begin{abstract}
Objective (s): Single child behavior affects very low fertility with negative growth rate and lack of replacement. In this study was attempted to investigate the prevalence and determinants of single child behavior amongst women living in Fars province, Iran.

Methods: The present study was conducted using the analysis of the 2016 census micro-data. The statistical population was comprised of married women having one children. A $2 \%$ sample was selected for this second analysis. The individual and residential characteristics were used as the independent variables.

Results: In all the data for 15076 women were analyzed. Single child was more prevalent among women with higher education as well as employed women than other their counterparts. The findings suggested that the odds of single child for the women who were living in an apartment as well as those who were resident in a rented house was more than counterparts. With increasing overcrowding, the probability of single child increased. Increasing the area of the living places had significantly reduced the probability of single child.

Conclusion: The best population policy for achieving the higher fertility rate and replacement fertility level is attention to the housing policy. Continuing the current housing status can may lead to the more prevalence of single child in the province.
\end{abstract}

Key Words: Women, Single Child, Housing Status, Employment Status, Education

\footnotetext{
* Corresponding author: Faculty of Economics, Management and Social Sciences, Shiraz University, Shiraz, Iran

E-mail: serajmahmoudiani@gmil.com
} 


\title{
بررسى شيوع و عوامل مؤثر بر رفتار تكفرزندى در بين زنان: مطالعه موردى در استان فارس
}

\author{
سراج الدين محموديانى \\ 1. إنشكده اقتصاد، مديريت و علوم اجتماعى، دانشكاه شيراز، شيراز، ايران

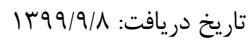

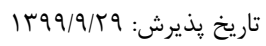

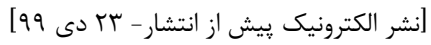

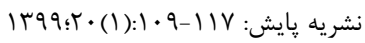

جكيده

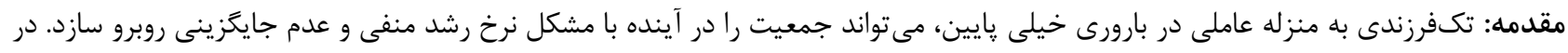

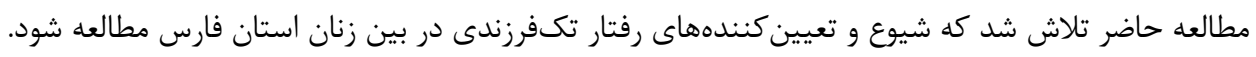

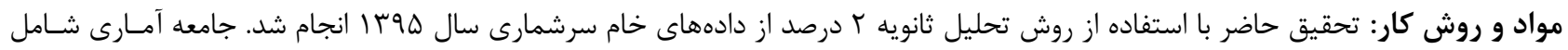

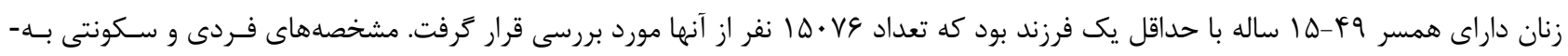

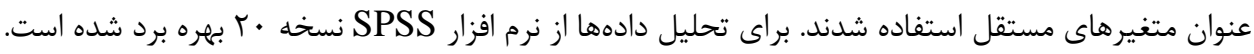

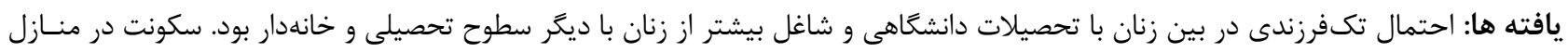

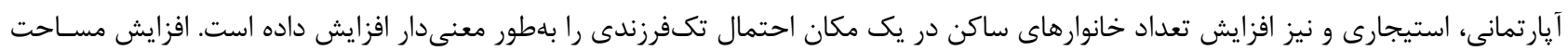

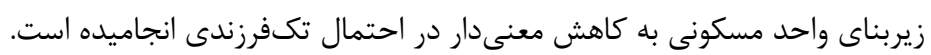

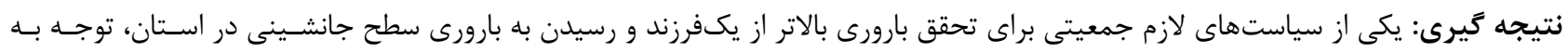

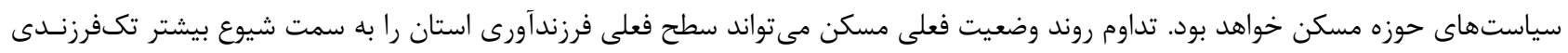
سوق دهد. كليدوازه: زنان، تكفرزندى، وضعيت مسكن، وضعيت اشتغال، تحصيلات 
فردى، متفاوت از ديخر افرادند و اين تفاوت اغلب خود را بــهـ صـورت

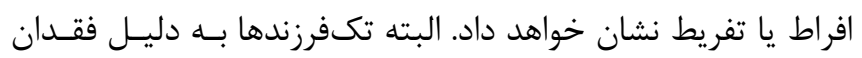

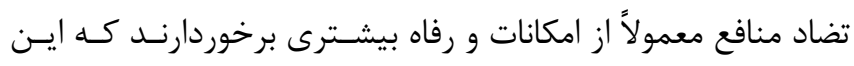

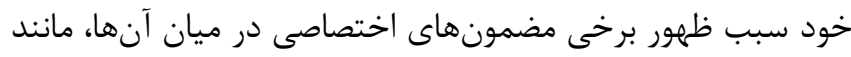

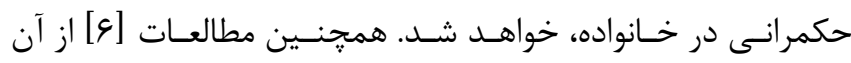

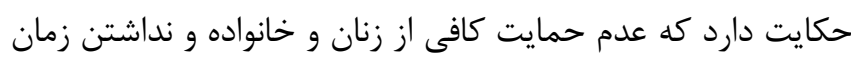

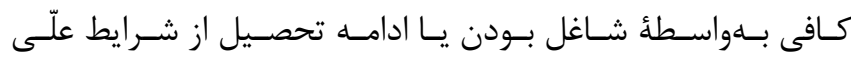

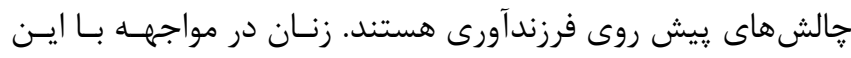

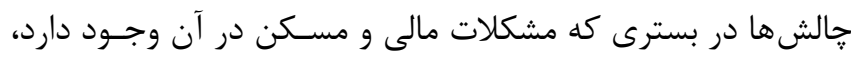

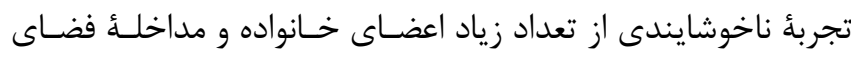

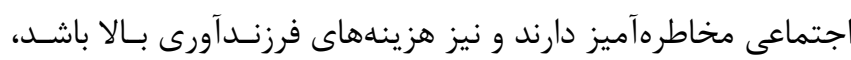

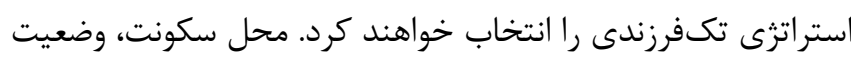

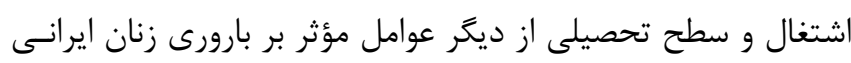

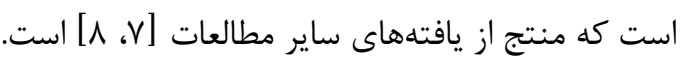

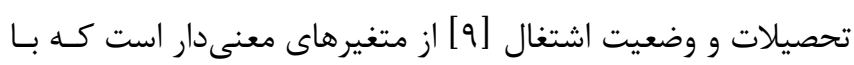

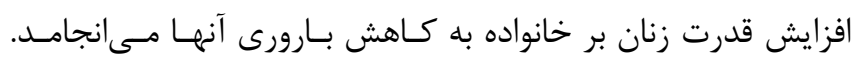

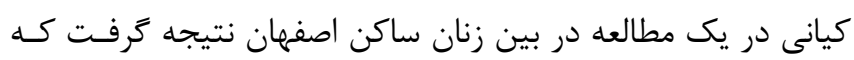

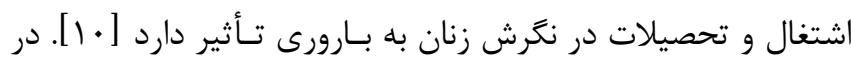

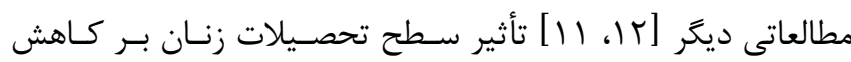

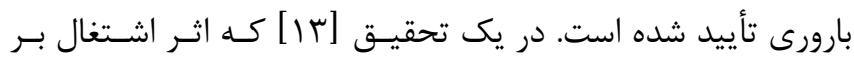

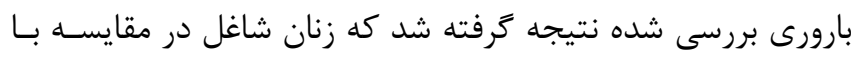

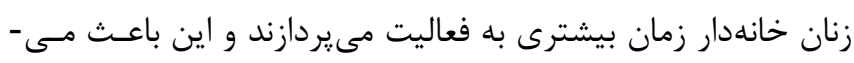

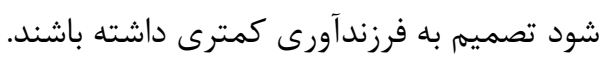

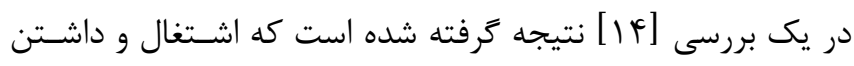

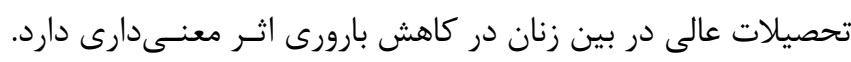

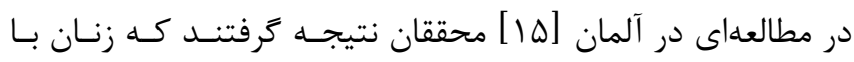

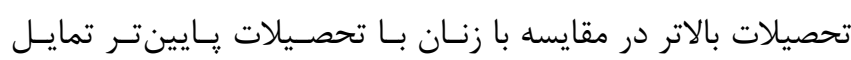

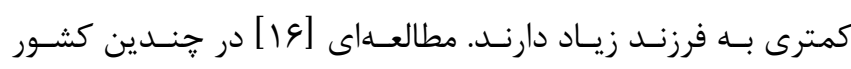

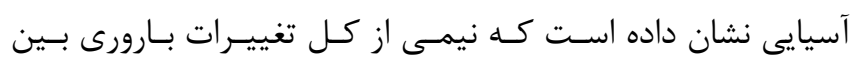

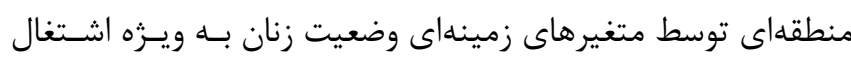

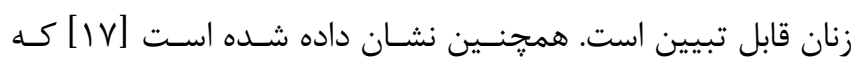

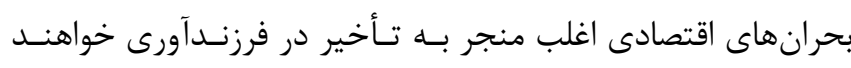

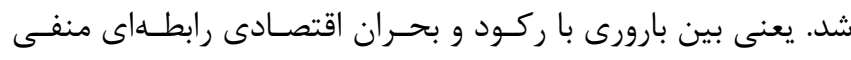

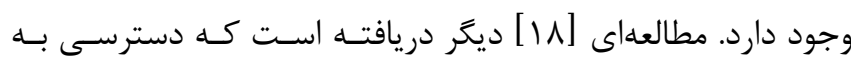

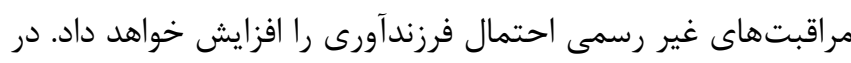

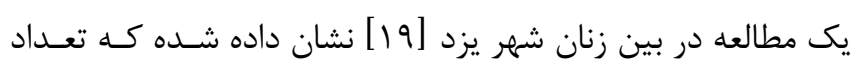

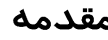

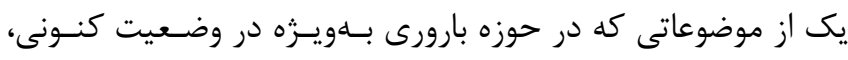

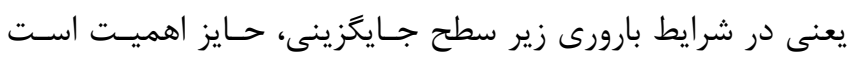

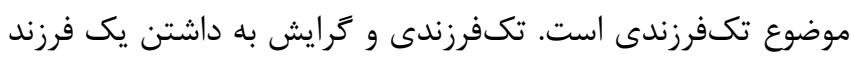

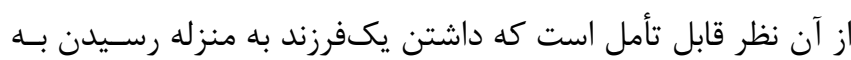

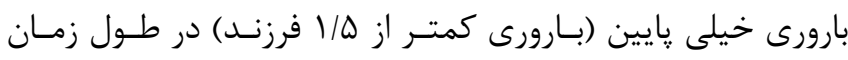

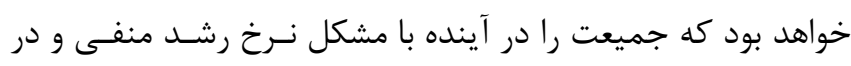

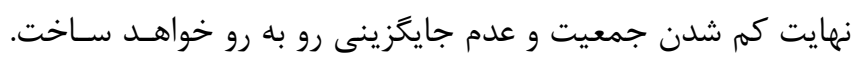

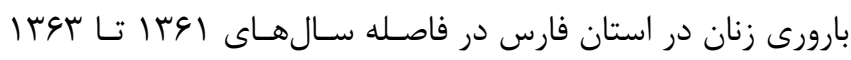

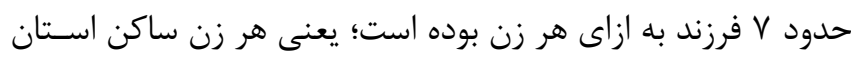

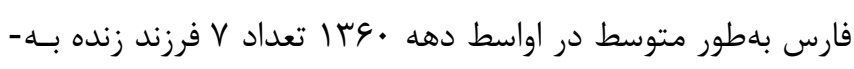

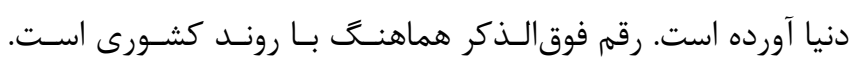

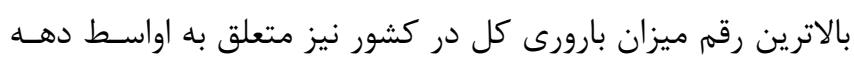

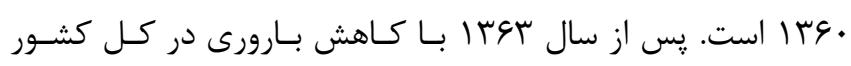

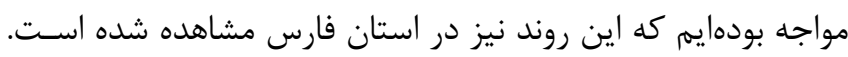

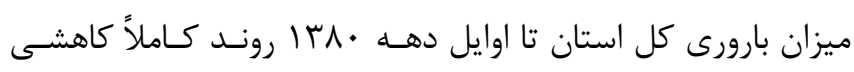

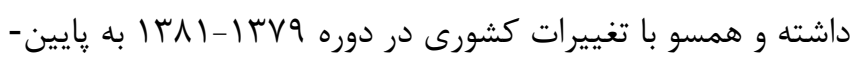

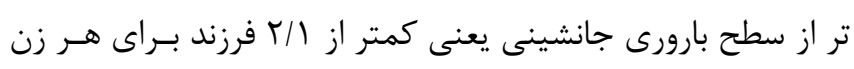

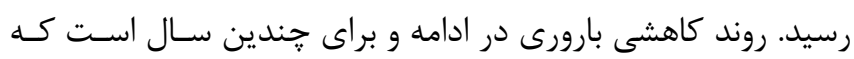

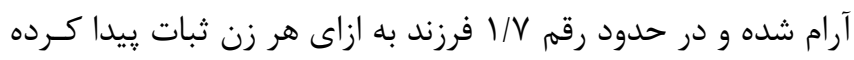

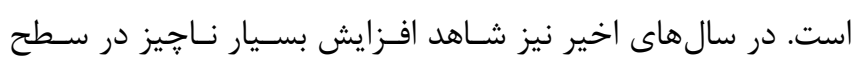

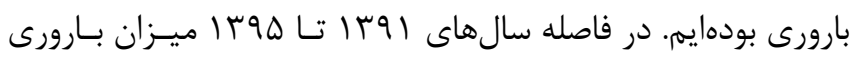

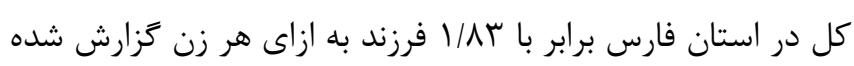

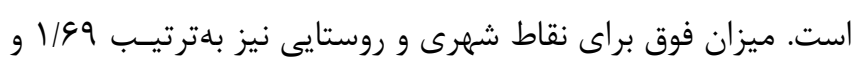

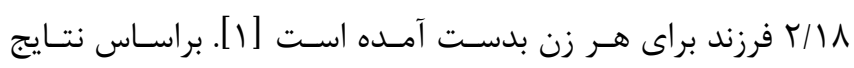

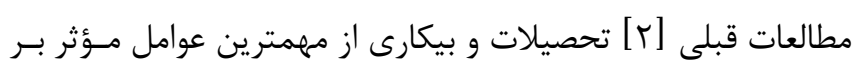

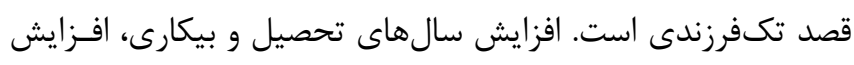

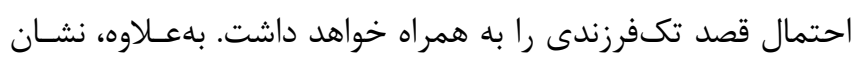

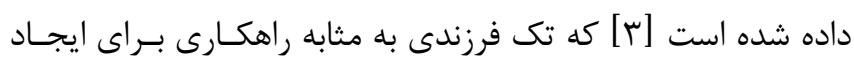

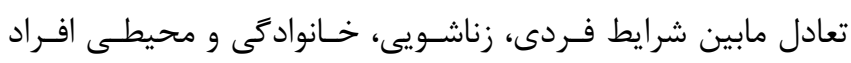

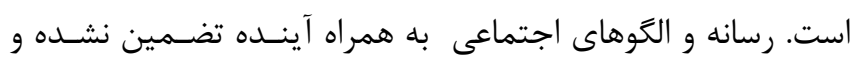

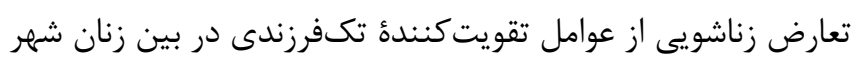

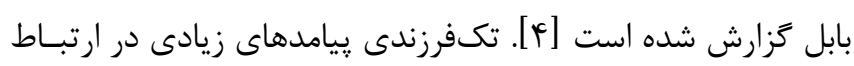

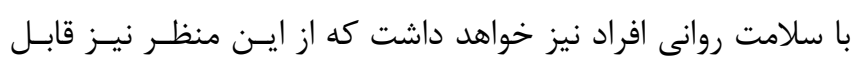

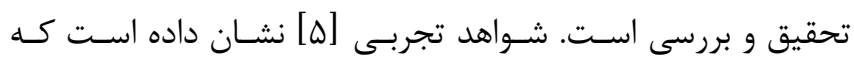

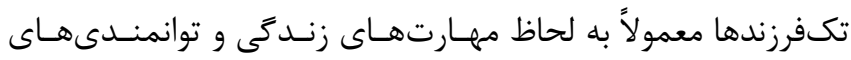


يافتهها تحليل دادهها (جدول () گَوياى آن است كه بـيش از •ـ درصـد از

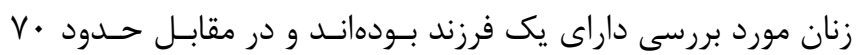

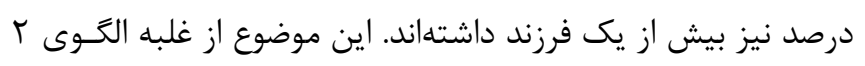

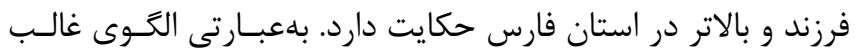

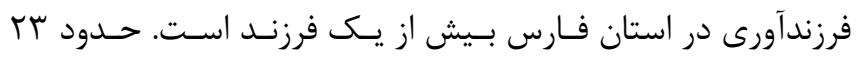

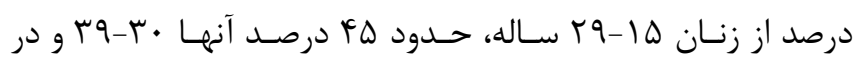

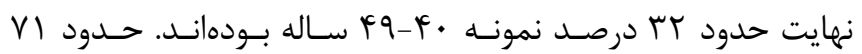

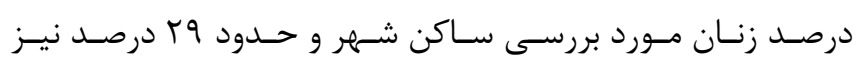

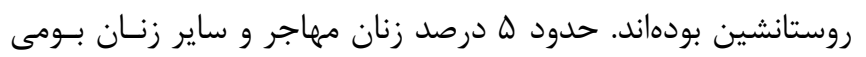
استان فارس بهشمار آمدهاند.

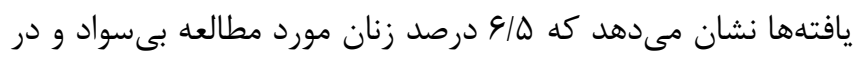

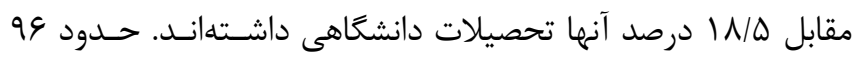

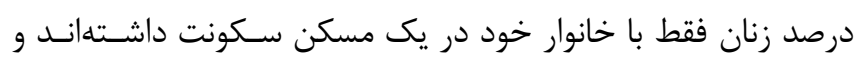

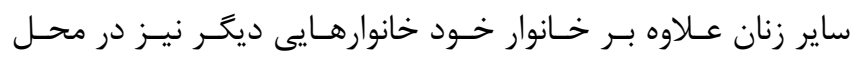

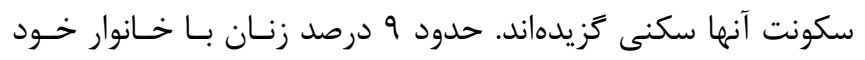

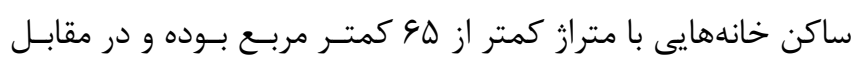

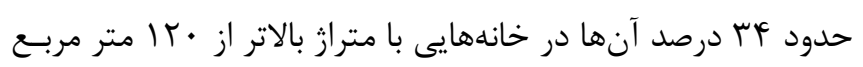
سكونت داشتهاند.

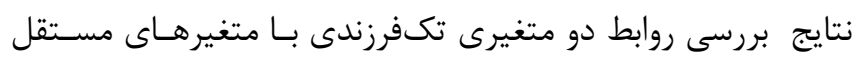

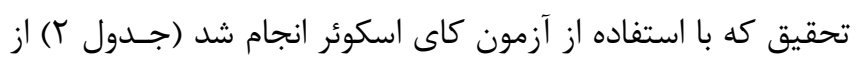

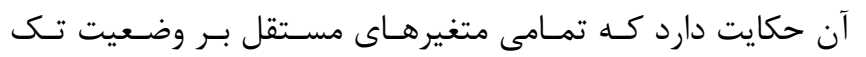

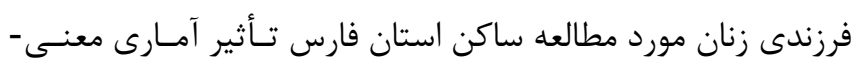

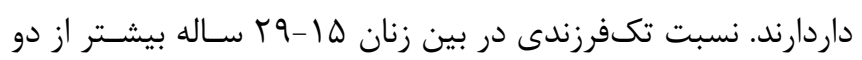

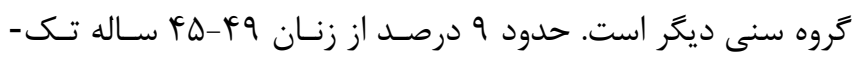

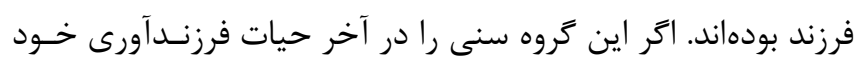

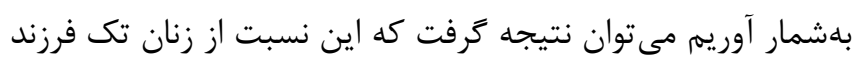

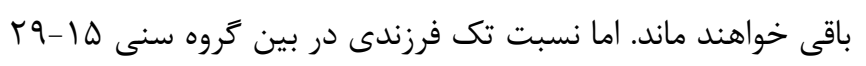

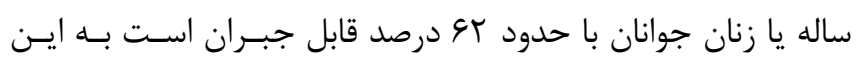

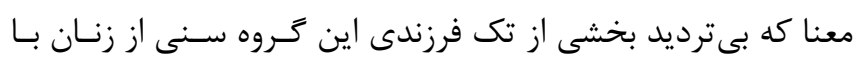

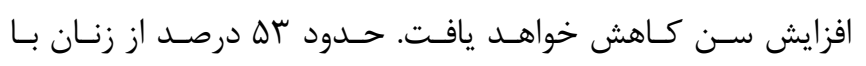

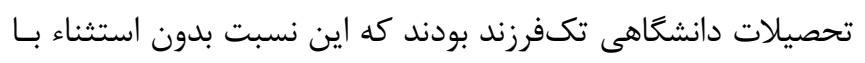

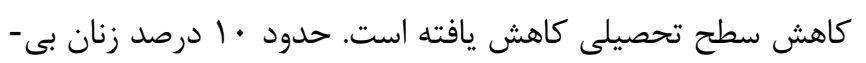

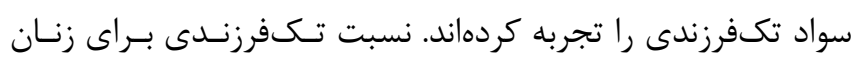

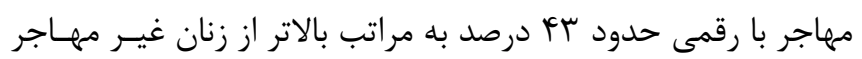

فرزندان ايدهآل زنان مورد مطالعه نسبت به سالهاى كذشته كاهش

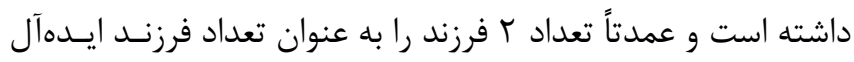

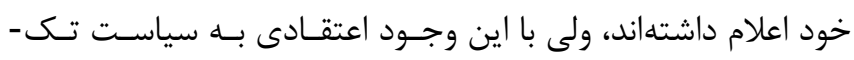

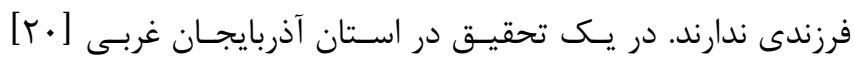

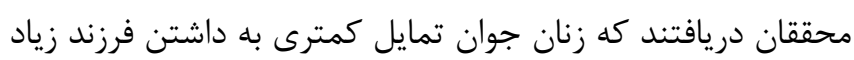

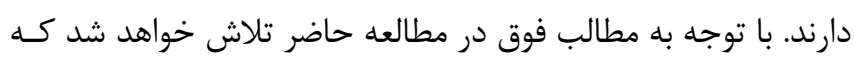

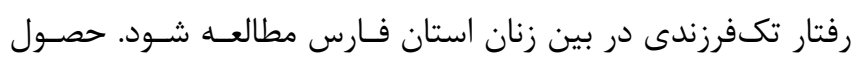

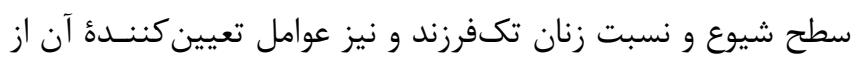
اهداف مطالعه حاضر است.

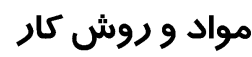

مطالعه كمى حاضر با استفاده از روش تحليل ثانويه دادههاى موجود

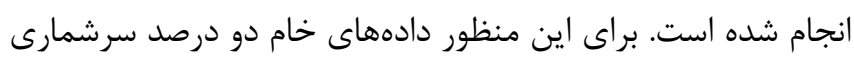

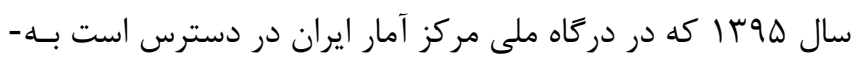

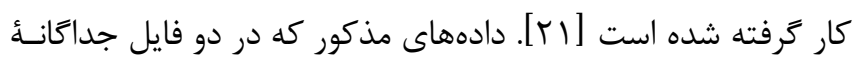

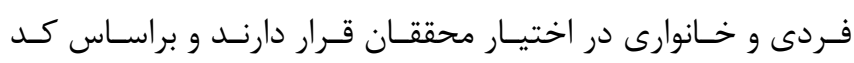

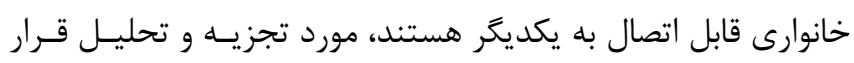

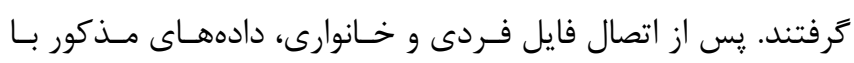

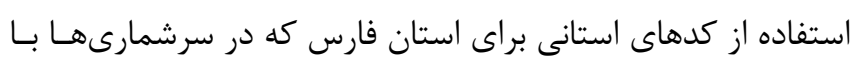
كد V • مشخص مى شود انتخاب شد.

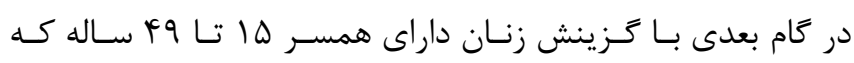

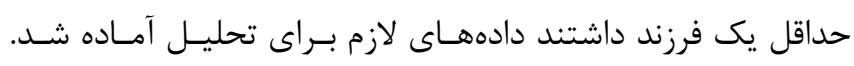

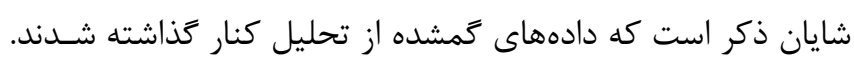

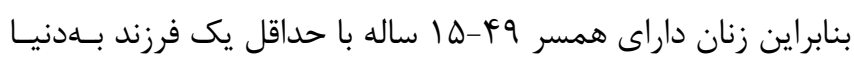

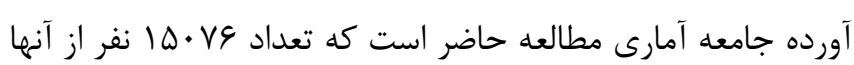
مورد بررسى قرار كرفت. متغيرهاى مستقل فردى شامل سماض سن، محسل

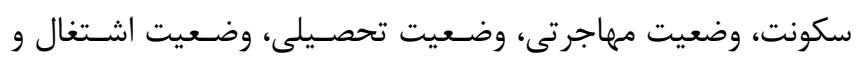

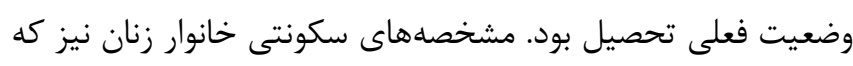

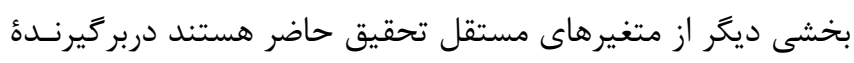

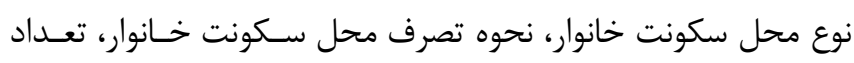

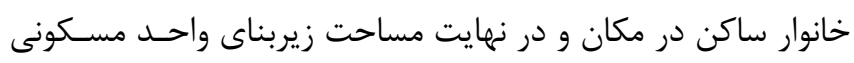

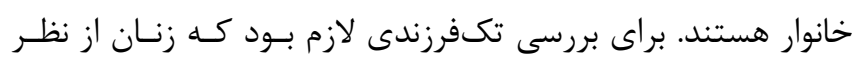

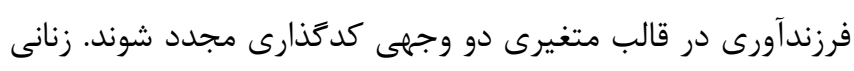

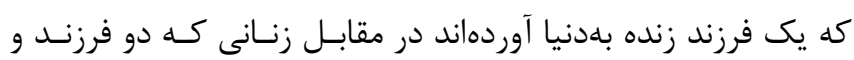
بالاتر دارند بهعنوان متغير وضعيت تك فرزندى تعريف شد. 
يافتها (جدول ؟r) نشان مى دهند كه با افزرايش سـن احتمـال تـك فرزندى در بين زنان مورد مطالعه كاهش خواهد يافت و رابطه فـوق احت

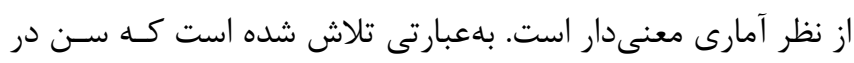

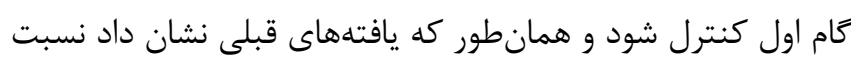

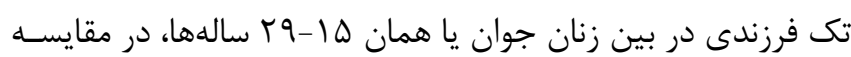

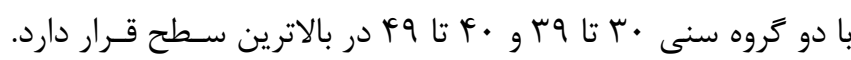

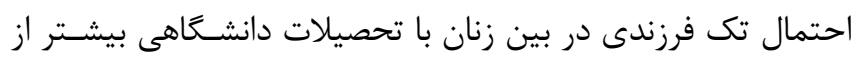

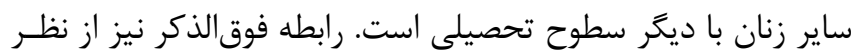

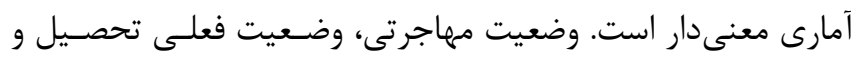

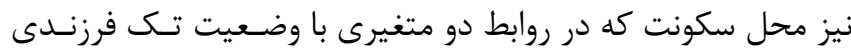
رابطه معنى دار داشتند در تحليل جند متغيرى معنى دارى خود را راز

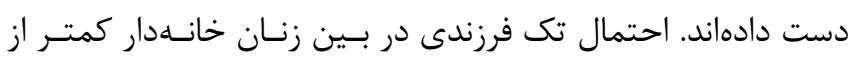
زنان شاغل است. سكونت در مسكنهاى غير آيارتمانى و شخصى احتمال تكفرزنسـى آنى

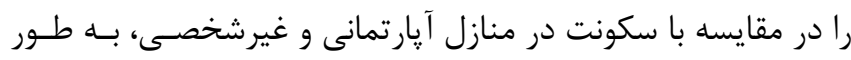

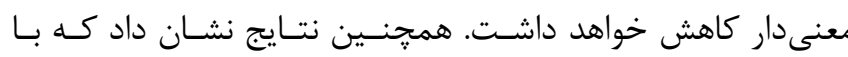
افزايش تعداد خانوارهاى ساكن در يك مكان احتمال تكفرزندى به طور معنىدارى افزايش خواهد يافت. افزايش مساحت زيربناى واحد مسكونى نيز به كاهش معنى دار احتمال تكى فرزندى مى إنجامد.

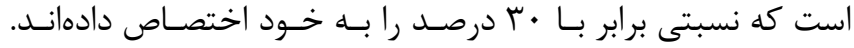
نسبت تكفرزندى در بين زنان شـاغل بيشـتر از همتايـان خانـهدار

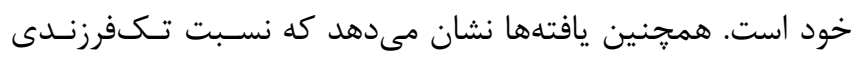

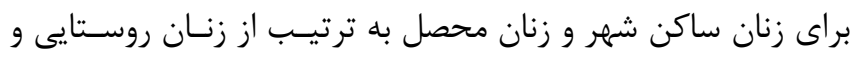

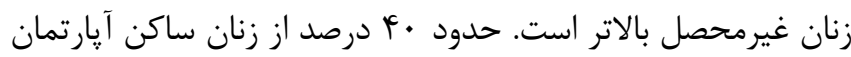

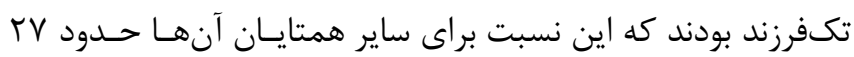

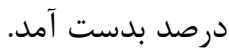

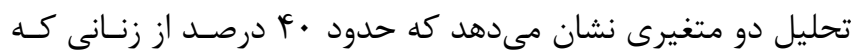

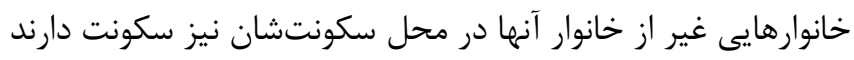

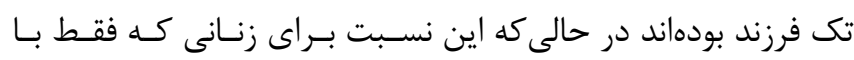

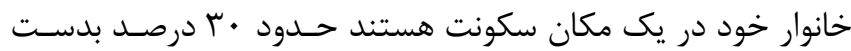

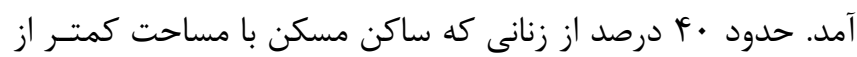

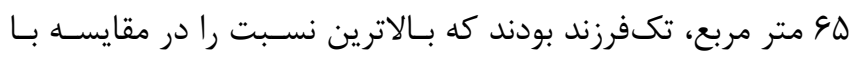

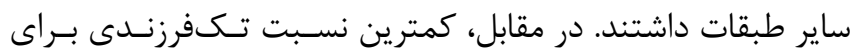

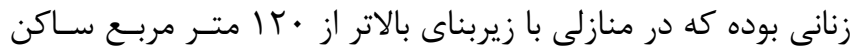

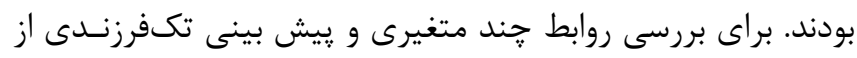

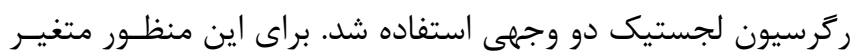
وابسته به شكل متغيرى اسمى دو وجهى بـ با كدهاى صفر و يـــ وارد

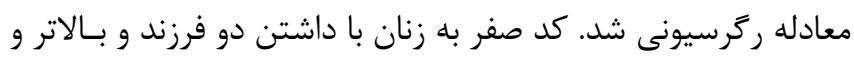
كد يك براى زنان تك فرزند اختصاص داده شد. 


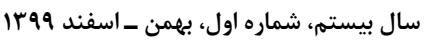

نشريه يثروشكده علوم بهداشتى جهادانشگاهى

جدول ا: توزيع نمونه مورد مطالعه برحسب مشخصههاى فردى و سكونتى

\begin{tabular}{|c|c|c|}
\hline درصد & فراوانى & \\
\hline$r \cdot / f$ & $f \Delta \wedge\rangle$ & تك فرزند \\
\hline $99 / 9$ & $1 \cdot 4 \wedge 9$ & دو فرزند و بالاتر \\
\hline درصد & 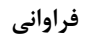 & كروههاى سنى (سال) \\
\hline$r M / F$ & rara & $r q-10$ \\
\hline$f \& / q$ & GVVT & гq-г. \\
\hline$T 1 / 9$ & fraq & kq-r. \\
\hline درصد & 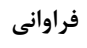 & محل سكونت \\
\hline$v \cdot / 9$ & $1.91 \mathrm{~F}$ & شهر \\
\hline$r q / 1$ & frat & روستا \\
\hline درصد & فراوانى & وضعيت مهاجرتى \\
\hline$\Delta / f$ & $\wedge 1$. & مهاجر \\
\hline $94 / 9$ & IFTGG & غير مهاجر \\
\hline درصد & فراوانى & وضعيت تحصيلى \\
\hline $9 / 0$ & $9 \vee r$ & 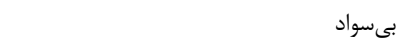 \\
\hline rI/A & ret & ابتدايى \\
\hline $19 / \pi$ & r人q4 & راهنمايى \\
\hline$r F /$. & DIrg & متوسطه/ دييلم/ پيش دانشگاهى \\
\hline $1 N / \Delta$ & rVAN & دانشعاهى \\
\hline درصد & 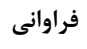 & وضعيت فعلى تحصيل \\
\hline 1/9 & TFF & محصل \\
\hline $91 / 4$ & IfNTr & غير محصل \\
\hline درصد & فراوانى & وضعيت اشتغال \\
\hline $10 / 0$ & THFF & شاغل \\
\hline$\Lambda F / \Delta$ & ITVTr & غير شاغل \\
\hline درصد & 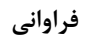 & نوع محل سكونت خانوار \\
\hline$r F / 1$ & 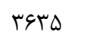 & آإرتمان \\
\hline$V \Delta / 9$ & ||$F+\mid$ & غير آيارتمان \\
\hline درصد & 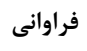 & نحوه تصرف محل سكونت خانوار \\
\hline$\Delta V / l$ & $\wedge \notin 11$ & شخصى \\
\hline$r F / D$ & $\Delta T \cdot \Lambda$ & رهن/استيجارى \\
\hline$\Lambda / r$ & ITUV & ساير \\
\hline د - مرصد & فراوانى & تعداد خانوار ساكن در مكان \\
\hline $99 / \pi$ & $|f \Delta| \Lambda$ & يك خانوار \\
\hline$r / V$ & $\Delta \Delta \Lambda$ & دو خانوار و بيشتر \\
\hline درصد & فراوانى & مساحت زيربناى محل سكونت (متر مربع) \\
\hline$\Lambda / V$ & 1111 & كمتر از \\
\hline $19 / 5$ & r人१ & q. 9 . 90 \\
\hline$r V / V$ & r\&AD & $|r \cdot| r q 1$ \\
\hline$r F / F$ & DIAV & بالاتر از • rا \\
\hline
\end{tabular}


سال بيستم، شماره اول، بهمن - اسفند 99

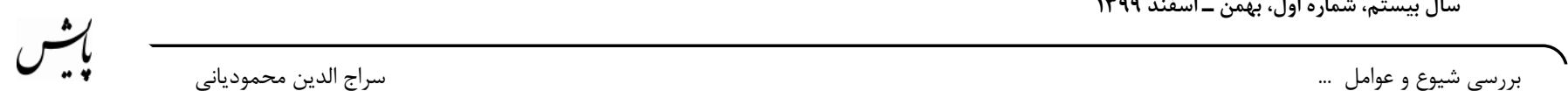

جدول r: توزيع وضعيت تكفرزندى نمونه مورد مطالعه برحسب مشخصه هاى فردى و سكونتى

\begin{tabular}{|c|c|c|c|c|}
\hline تعداد نمونه & خرزند & بله & & \\
\hline Tata & $r V / 9$ & $G T / F$ & $r q-10$ & \multirow{3}{*}{$\begin{array}{r}\text { سن (.) }{ }^{2} \\
* r v / r q 4 .{ }^{2}=\chi\end{array}$} \\
\hline sVVT & $V I / r$ & TN/V & ५१-r. & \\
\hline pVeq & $9 \cdot / 9$ & $9 / 1$ & $p q-r$. & \\
\hline $9 \vee r$ & $q \cdot / r$ & $9 / \mathrm{V}$ & 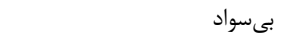 & \multirow{4}{*}{ 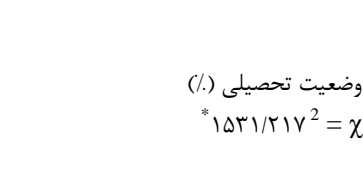 } \\
\hline rTAT & $\Lambda \& / \pi$ & $\mid r / \Lambda$ & ابتدايى & \\
\hline r^৭ץ & $V N / \Delta$ & $r \mid / \Delta$ & راهنمايى & \\
\hline DIrq & $9 T / \cdot$ & 「N/• & متوسطه/دييله/ يیش دانشكاهى & \\
\hline TYMA & $F V / r$ & $\Delta T / V$ & دانشگاهى & \\
\hline IFTGG & $V \cdot / r$ & $r q / V$ & غير مهاجر & وضعيت مهاجرتى (./) \\
\hline$\wedge 1$. & $\Delta \xi / \Lambda$ & Fr/T & مهاجر & $* \varphi 91 \cdot \wedge v^{2}=\chi$ \\
\hline TMFY & $94 / \pi$ & $r \Delta / V$ & 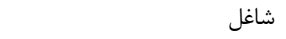 & وضعيت اشتغال (./) \\
\hline ITVT & $v \cdot 1 \Delta$ & $r q / \Delta$ & غيرشاغل & $* r \Delta / ৭ q v^{2}=\chi$ \\
\hline $1.9 \wedge \mathrm{F}$ & $9 V / 9$ & $r T / l$ & شهر & محل سكونت (.) \\
\hline frat & $V \pi / V$ & $r \varepsilon / T$ & ل روستا & $* \leftarrow q / \wedge q .{ }^{2}=\chi$ \\
\hline rFF & $F \psi / V$ & $\Delta \Delta / \Gamma$ & محصل & وضعيت فعلى تحصيل (./) \\
\hline IFNTK & $\vee \cdot / \cdot$ & $r \cdot / \cdot$ & غيرمحصل & $* V r / \varepsilon \Delta r^{2}=\chi$ \\
\hline rgTd & $4 \cdot / 1$ & rq/q & آيارتمان & نوع محل سكونت خانوار (./) \\
\hline$\| F F \mid$ & $V r / 9$ & $r V / F$ & غير آيارتمان & $* r \cdot \Delta / \cdot r \varphi^{2}=\chi$ \\
\hline 1911 & $v \& / 9$ & $r M / F$ & شخصى & \multirow{3}{*}{ 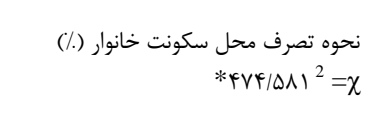 } \\
\hline$\Delta T \cdot \Lambda$ & $4 \cdot 1 \cdot$ & $\varphi \cdot / \cdot$ & رهن/ استيجارى & \\
\hline ITDV & $9 \cdot 19$ & $r q / 4$ & ساير & \\
\hline$|f \Delta| \Lambda$ & $99 / 9$ & $r \cdot / l$ & يك خانوار & تعداد خانوار ساكن در مكان \\
\hline$\Delta \Delta \Lambda$ & $\Delta 9 / 9$ & $4 \cdot / 1$ & دو خانوار و بيشتر & \multirow{5}{*}{ 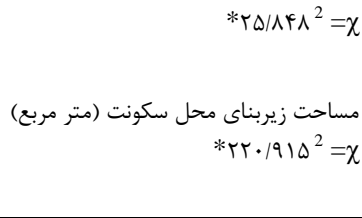 } \\
\hline 1411 & $\Delta १ / १$ & $r \cdot / 1$ & كمتر از SD & \\
\hline КА१ & $q \pi / 4$ & re/s & 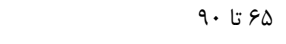 & \\
\hline$\Delta \& \wedge \Delta$ & $9 N / 9$ & $r M / 1$ & $|r \cdot| r 9 \mid$ & \\
\hline DIAV & $v e / r$ & rr/A & بالاتر از • با & \\
\hline
\end{tabular}

جدول ץ: تحليل ركر سيونى تك فرزندى در بين زنان مورد مطالعه با استفاده از ركر سيون لُجستيك

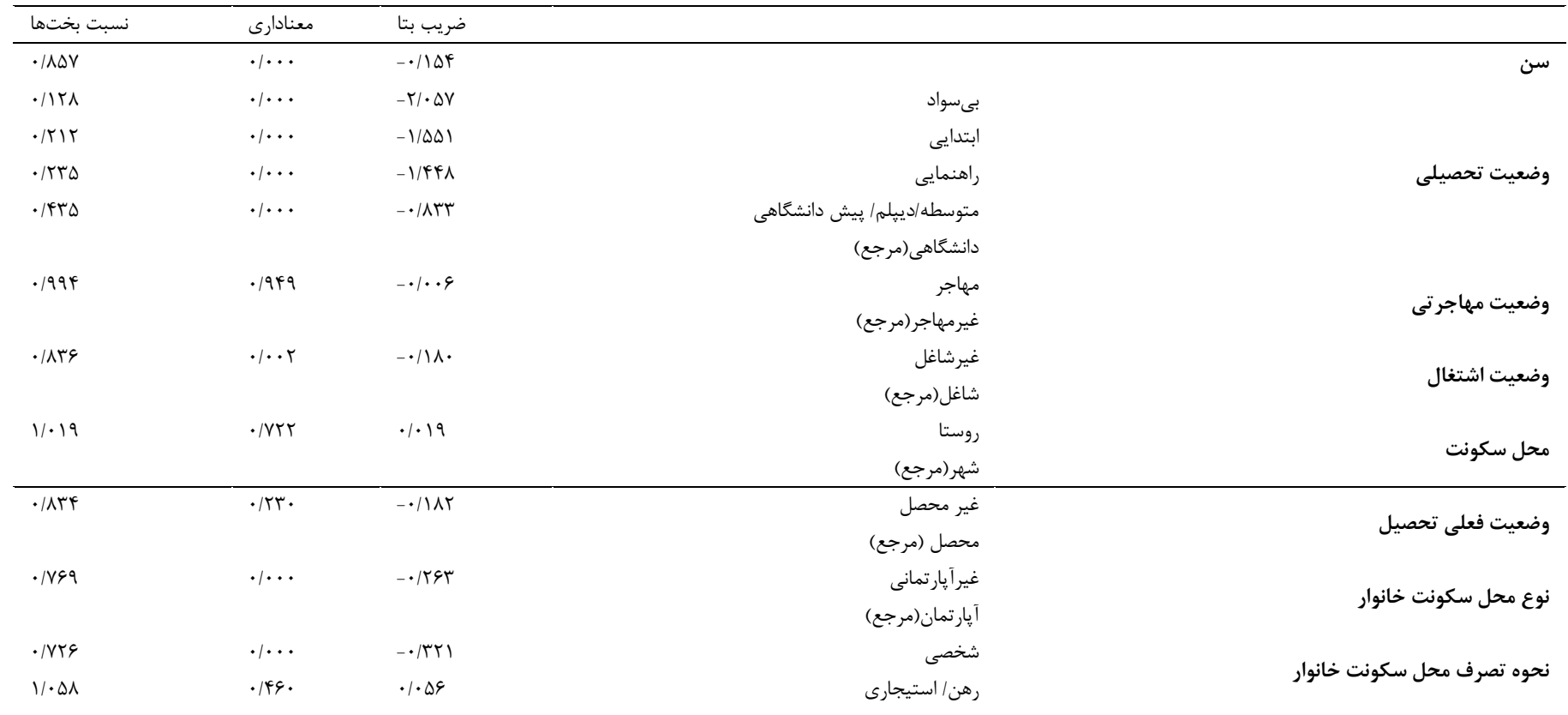


متغيرهاى مذكور در يــيش بينسى وضـعيت تـكفرزنسـى در اسـتان

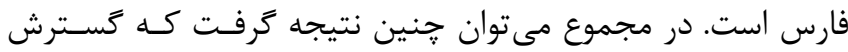

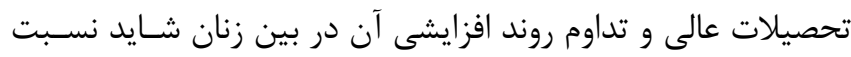

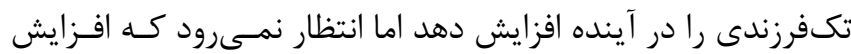

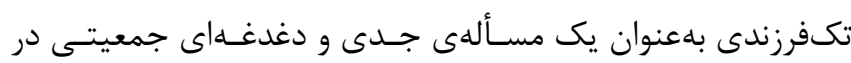

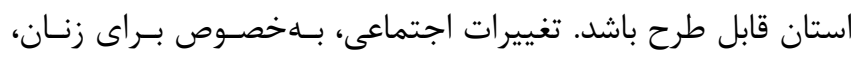

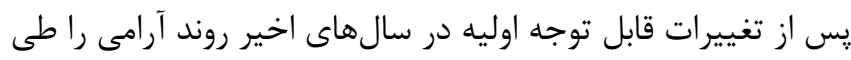

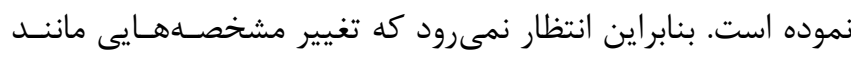

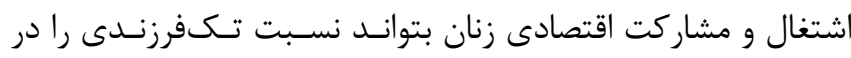

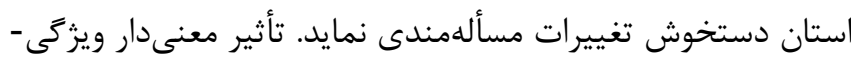

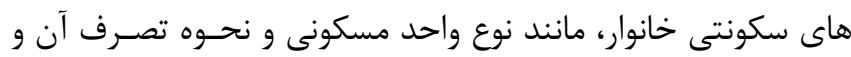

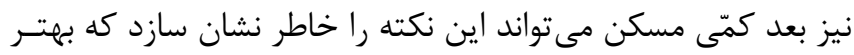

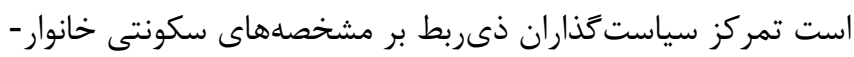

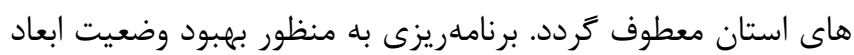

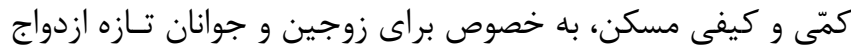

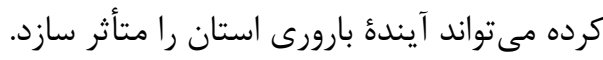

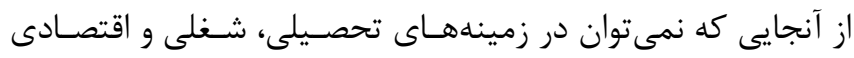

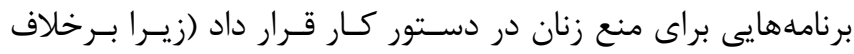

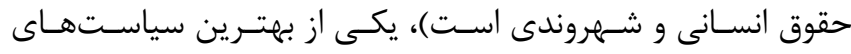

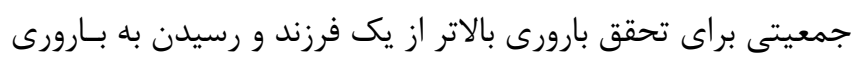

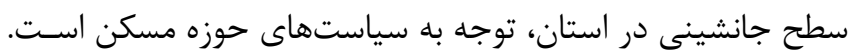

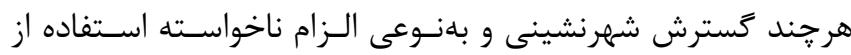

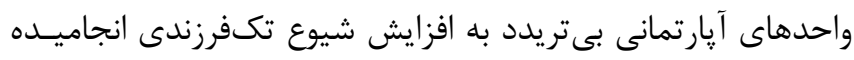

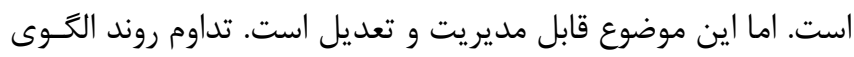

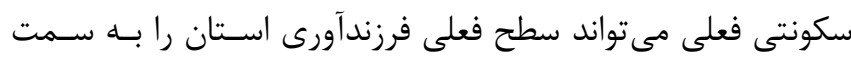

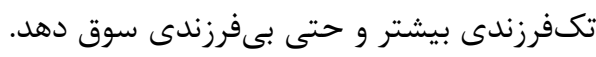

\section{سمم نويسند}

سراجالدين محموديانى: نكارش مقاله

\section{بحث و نتيجه گيرى}

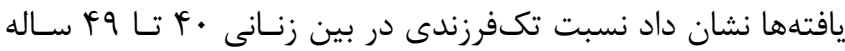

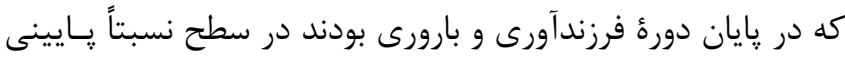

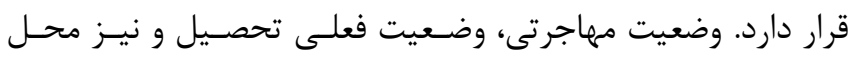

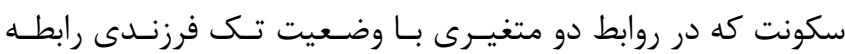

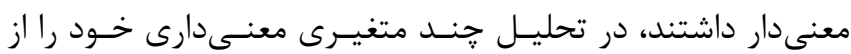

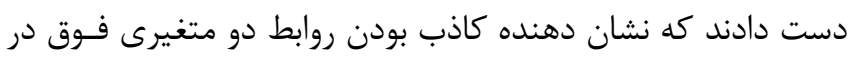

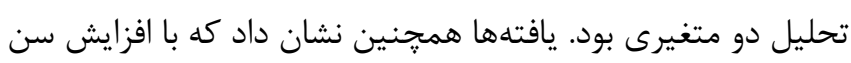

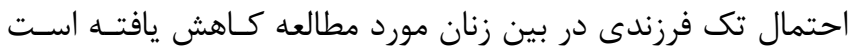

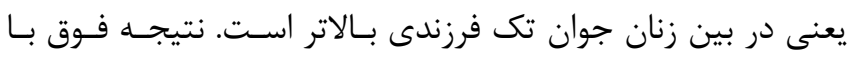

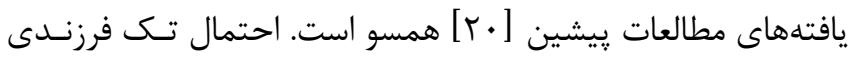

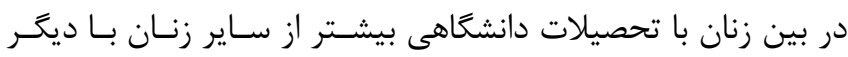

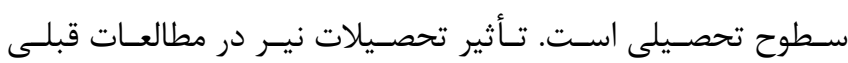

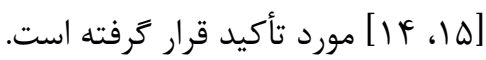

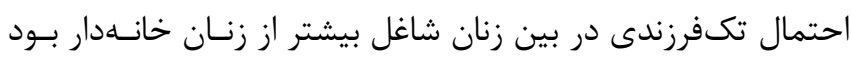

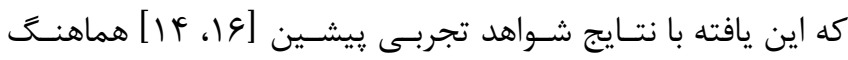

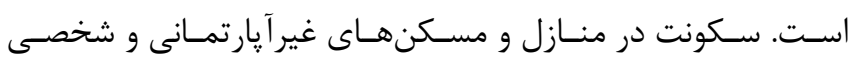

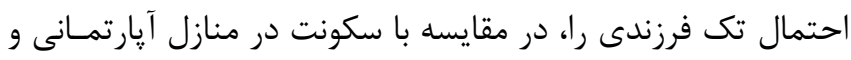

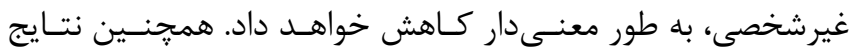

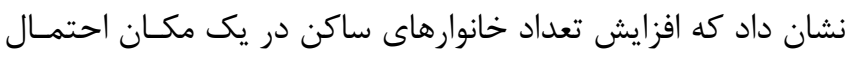

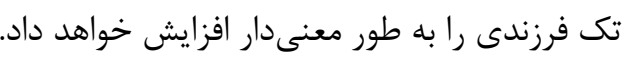

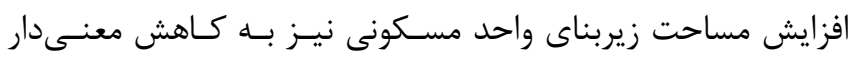
احتمال تكفرزندى خواهد انجاميد. يافتههاى فوقالـذكر بيـانكر ارتبـاط

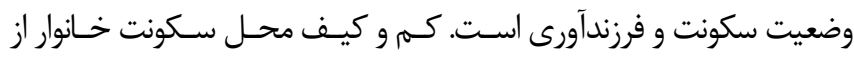

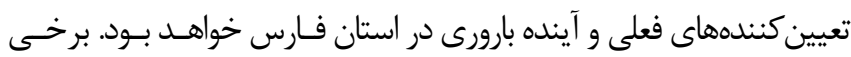

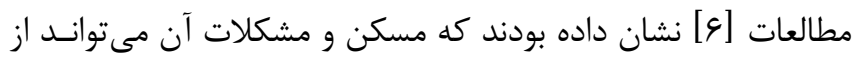

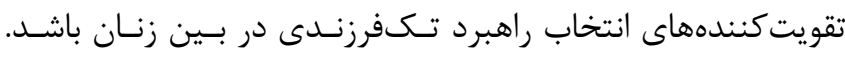

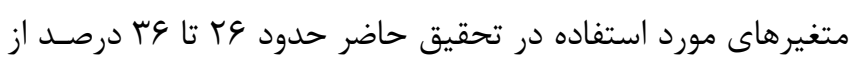
احتمال تكفرزندى توسط متغيرهاى مورد استفاده در الكوى قابليت

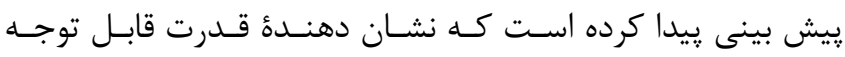




\section{منابع}

1. The statistical center of Iran. The total fertility rate based on the 2016 census during 2012 to 2016 period. Tehran: The statistical center of Iran; 2016 [Persian] https://www.amar.org.ir/Portals/0/News/1396/2_barvari.pdf 2. Khalajabadi Farahani F, Saraie H. Intention for Single Child among Women and Men on the Threshold of Marriage in Tehran: Levels and Determinants. Iranian Population Studies 2013; 1: 6185 [Persian]

3. Khalajabadi Farahani F, Saraie H. Exploration of underlying factors for single child intention and behavior in Tehran: a Qualitative Study. Women's Strategic Studies 2016; 1: 29-58 [Persian] https://dx.doi.org/10.22095/jwss.2016.33826

4. Behmanesh F, Taghizadeh Z, Vedadhir A, Ebadi A, Pourreza A, Abbasi-Shavazi M. Explaining the causes of single child based on women's views: A qualitative Study. Iranian Journal of Epidemiology 2019; 15: 279-288 [Persian] URL: http://irje.tums.ac.ir/article-1-6387-fa.html

5. Shojaei J, Yazdkhasti B. One-child living experience: a study of girls over 18 years. Women in Development and Politics 2018; 15: 447-476 [Persian] https://dx.doi.org/10.22059/jwdp.2017.238489.1007242

6. Jahangiri J, Ahmadi H, Tabiee M, Moltafet $\mathrm{H}$. Construction of one child women understanding of childbearing challenges (Participants: one-child women of Ahvaz). Social Development 2014; 9: 85110 [Persian]

7. Mahmoudiani S. Explaining the married women's fertility in reproductive age in Iran using Hierarchical Linear Model. Payesh 2020; 19: 289-297 [Persian] http://payeshjournal.ir/article-1-1381-en.html 8. Mahmoudiani S. Multi-level analysis of interprovincial differences in fertility in Iran: The case of six provinces with high and low fertility rates, Journal of Health Sciences and Surveillance System 2020; 8: 128-133 http://dx.doi.org/10.30476/jhsss.2020.86833.1100 9. Mahmoudiani S, Ahmadi A, Abbsi K. A study on relationship between power structure in the family and women's fertility behavior in the city of Lar, Fars Province. Women's Strategic Studies 2019; 22: 73-98 [Persian] DOI: 10.22095/JWSS.2019.109567
10. Kiani M. Women's attitude to fertility in Iran: A case study in Isfahan, Iran. The Social Sciences 2011; 6: 398-403

http://dx.doi.org/10.3923/sscience.2011.398.403

11. Dreze J, Murthi M. Fertility, education and development: evidence from India. Population and Development Review 27: 33-63 https://www.jstor.org/stable/2695154

12. Rios-Neto ELG, Miranda-Ribeiro A, MirandaRibeiro P. Fertility differentials by education in Brazil: from the conclusion of fertility to the onset of postponement transition. Population and Development Review 2018; 44: 489-517

13. Ghazi_Tabatabaea M. The impact of women's employment on fertility in Iran. Women in Development and Politics 2013; 11: 29-44 [Persian] https://dx.doi.org/10.22059/jwdp.2013.35473

14. Lam G. How does gender equity affect fertility in Hong Kong? $1^{\text {st }}$ Edition, The University of Science and Technology: Republic of China, 2007

15. Kreyenfeld M, Konietzka D. Education and fertility in Germany. In: Kreyenfeld M, Konietzka D, eds. Demographic changes in Germany. $1^{\text {st }}$ Edition, Springer Publication: Berlin, 2008:165-187

16. Hirschman C, Guest PH. Multilevel models of fertility determination in four southeast Asian countries: 1970 and 1980. Demography 1990; 27: 369-396

17. Sobotka T, Skirbekk V, Philipov D. Economic recession and fertility in the developed world. Population and Development Review 2011; 37: 267306 https://www.jstor.org/stable/23043283

18. Hank K, Kreyenfeld M. A multilevel analysis of child care and women's fertility decisions in western Germany. Journal of Marriage and Family 2003; 65: 584-596 https://www.jstor.org/stable/3600025

19. Abbasi-Shavazi MJ, Askari-Nodoshen A. Family changes and fertility decline in Iran: the case of Yazd province. Journal of Social Sciences Letter 2005; 11: 35-75 [Persian]

20. Mahmoudi M, Zeraati H, Akabri A, Majlesi F. Study of the relationship of socioeconomic and demographic factors with fertility. Journal of Sabzevar University of Medical Sciences 2008; 15: 40-45 [Persian]

21. The Statistical Centre of Iran. The census microdata of population and housing in 2016. The Statistical Centre of Iran: Tehran, 2016 https://www.amar.org.ir 